\title{
A Virtual and Comparative Study on Soil Features and its Managing Ability
}

\section{OPEN ACCESS}

Manuscript ID:

ASH-2021-09013808

Volume: 9

Issue: 1

Month: July

Year: 2021

P-ISSN: 2321-788X

E-ISSN: 2582-0397

Received: 05.03.2021

Accepted: 14.05.2021

Published: 01.07.2021

Citation:

Narayanan, Anuja. "A Virtual and Comparative Study on Soil Features and Its Managing Ability." Shanlax International Journal of Arts, Science and Humanities, vol. 9, no. 1, 2021, pp. 159-163.

DOI:

https://doi.org/10.34293/ sijash.v9i1.3808

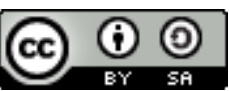

This work is licensed under a Creative Commons Attribution-ShareAlike 4.0 International License

\section{Anuja Narayanan}

Assistant Professor, Department of Civil Engineering

Mepco Schlenk Engineering College, Sivakasi, Tamil Nadu, India

(D) https://orcid.org/0000-0003-2586-4895

\section{Abstract}

The study is related to the comparison of soil characteristics in some areas from a depth of $1 \mathrm{~m}, 1.2 \mathrm{~m}$, and 1.5m; physical and geotechnical properties of the soil samples are studied in the laboratory to develop a simple method to determine the type of soil on a site. The tests conducted are grain size analysis, specific gravity, and field density. Moreover, the research intends to validate the behavior of sieving systems for different types of soils and at various loading conditions. From work, a decision support system to facilitate a sieving system that integrates geological, geotechnical, and structural factors is developed. The study reveals that an increase in the plasticity index decreases the angle of internal friction. The empirical models developed with the help of regression analysis for the benefit of field engineers for predicting the geotechnical properties.

Keywords: Soil characteristics, Grain size analysis, Specific gravity, Field density, Dry density, Sieve analysis

\section{Introduction}

In India, Black cotton soils form a major soil group and cover approximately $20 \%$ of the total area and are available at all places from Seehra (2008). Black cotton soil is characterized with high compressibility and plasticity, shrinkage, and swelling properties. Black cotton soil is the mostly referred, as expansive soils and therefore, its geotechnical properties are required to be investigated. The mineralogy of this soil is dominated by the presence of which is characterized by large volume change from wet to dry seasons, and vice versa (Raja Kumar 2014). Black cotton soil also facilitates compaction for obtaining the desired density with comparatively less compressive effort.

The black cotton soil also possesses low strength and undergoes excessive volume changes, making their use in construction is very difficult. The properties of the black cotton soil may be altered, viz mechanical, thermal, chemical, and other means. Therefore, it becomes very important to investigate the physical and engineering properties associated with the black cotton soil especially involved as a construction material and for foundation purposes. In the present study, three black cotton soil specimens are derived from a depth of 1 to $1.5 \mathrm{~m}$ which is studied in the laboratory for investigation of physical and engineering properties.

The various tests like grain size analysis, specific gravity, field density test, standard proctor compaction, consolidation and direct shear test are conducted on the soil specimens. Further, results are compared with the Indian Standard Code. Empirical models with the help of regression analysis developed in this study can improve the understanding of parameters involved for describing the characteristics of black cotton soil having medium plasticity and its use as construction material in roads and foundation purpose for the site engineers. 
This method is only used on fine-grained cohesive soils which do not contain any stones. It is, therefore very useful for the control of earthwork and subgrade materials but is not sustainable for coarse-grained pavement materials. The test involves jacking or hammering with a steel cylinder of known mass and volume into the soil, excavating it and finding the mass of soil contained in cylinder. The sieve analysis commonly known as gradation test, which is a basic essential test for all aggregates.

The sieve analysis determines the gradation (the distribution of aggregate particles, by size, within a given sample) in order to determine the compliance with design, production control requirements, and verification specifications. The gradation data may be used to calculate the relationships between various aggregates or aggregate blends, to check the compliance with such blends, and to predict the trends during production by plotting gradation curves graphically. It is used in conjunction with other tests, and the sieve analysis is good quality control and quality acceptance tool. The objectives are to determine the various soil samples for the purpose of usage in construction. To classify the soil samples using the unified soil classification.

\section{Experimental Works \\ Field Density Test}

To determine the in-situ dry density of finegrained natural or compacted soils free from aggregates using a core-cutter. From figure 1, the Cylindrical core-cutter - Seamless steel tube 130 $\mathrm{mm}$ long and $10 \mathrm{~cm}$ internal diameter with a wall thickness of $3 \mathrm{~mm}$. It should be beveled at one end. The cutter shall be kept properly greased or oiled. Steel dolly $-2.5 \mathrm{~cm}$ high and $10 \mathrm{~cm}$ internal diameter and wall thickness of $7.5 \mathrm{~mm}$ with a lip to enable it to be fitted on top of the core-cutter. Steel rammer with solid mild steel foot of $140 \mathrm{~mm}$ diameter and $75 \mathrm{~mm}$ height with a concentrically screwed $25 \mathrm{~mm}$ diameter staff. Overall length $\approx 900 \mathrm{~mm}$ and weight $\approx 9 \mathrm{Kg}$., Balance-Accurate to $1 \mathrm{~g}$., Palette knifehaving a blade approximately $20 \mathrm{~cm}$ long and $3 \mathrm{~cm}$ wide. The internal volume, $V c\left(\mathrm{~cm}^{3}\right)$ of the corecutter, is calculated from its dimensions. The weight, $W c(\mathrm{~g})$ of the core-cutter is measured. A small area, approximately, $30 \mathrm{~cm}$ square of the soil layer to be tested shall be exposed and leveled. The steel dolly shall be placed on top of the cutter and be rammed down vertically into the ground until only about 15 $\mathrm{mm}$ of the dolly protrudes above surface. The cutter shall then be dug out of the surrounding soil allowing some soil to project from the lower end of the cutter. The ends of the soil core shall then be trimmed flat to the ends of the cutter using the straight edge. Weight Ws (g) of the cutter plus the soil core is measured. The soil core shall be removed from the cutter and a representative sample is taken to determine water content, $w(\%)$. The above procedure should be repeated three times. The results are shown in Table 1.

Figure 1: Cylindrical Core Cutting

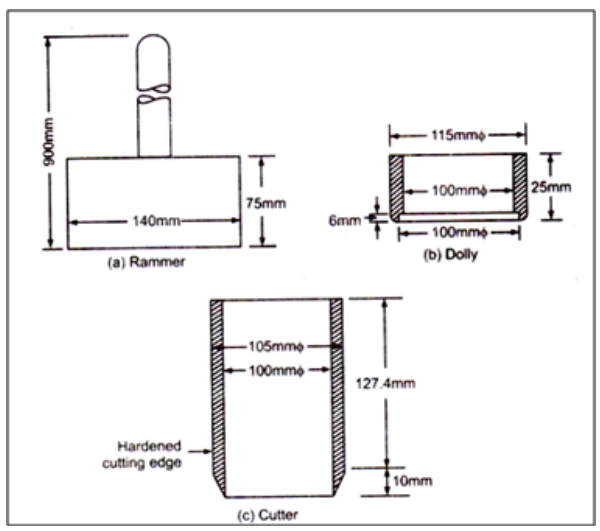

Table 1: Results of Field Density Test

\begin{tabular}{|l|c|c|c|}
\hline \multicolumn{1}{|c|}{ Observation } & $\begin{array}{c}\text { 1st } \\
\text { Reading }\end{array}$ & $\begin{array}{c}\text { 2nd } \\
\text { Reading }\end{array}$ & $\begin{array}{c}\text { 3rd } \\
\text { Reading }\end{array}$ \\
\hline $\begin{array}{l}\text { Mass of core cutter } \\
\text { wet soil (gm) }\end{array}$ & 2645 & 2580 & 2340 \\
\hline $\begin{array}{l}\text { Mass of core cutter } \\
(\mathrm{gm})\end{array}$ & 930 & 970 & 960 \\
\hline Mass of wet soil & 1715 & 1670 & 1640 \\
\hline $\begin{array}{l}\text { Volume of core } \\
\text { cutter }\end{array}$ & 1021.0 & 1021.0 & 1021.0 \\
\hline $\begin{array}{l}\text { Bulk density } \mathrm{P}=3 / 4 \\
\text { g/cm }\end{array}$ & 1.68 & 1.58 & 1.65 \\
\hline $\begin{array}{l}\text { Bulk unit weight } \mathrm{Y} \\
=9.81 \mathrm{P}\end{array}$ & 16.48 & 15.5 & 15.80 \\
\hline
\end{tabular}

\section{Sieve Analysis Test}

The sieve analysis is commonly known as the gradation test, is a basic essential test for all aggregates. The sieve analysis determines the 
gradation (the distribution of aggregate particles, by size, within a given sample) to determine compliance with design, production control requirements, and verification specifications. The gradation data may be used to calculate relationships between various aggregate or aggregate blends, to check compliance with such blends, and to predict trends during production by plotting gradation curves graphically, to name just a few uses. Used in conjunction with other tests, the sieve analysis is very good quality control and quality acceptance tool. Balance, Mechanical sieve shaker, if used, must provide a vertical or lateral and vertical motion to the sieve, causing the particles there on to bounce and turn to present different orientations to the sieving surface. Sieve shakers must provide sieving thoroughness within a reasonable time. Weight the sample to the nearest $1000 \mathrm{~g}$ by total weight of sample. This weight will be used to check for any loss of material after the sample has been graded. Select suitable sieve sizes by the specifications. Nest the sieves to decrease size from top to bottom and begin agitating and shaking the sample for a sufficient amount of time. For fine aggregate, round 8" (203.2 $\mathrm{mm}$ ) or 12" (304.8 mm) sieves are commonly used. These sieves are selfnesting and supported in a shaking mechanism at the top and bottom by various clamping and holding mechanisms. Small shakers of this type require shaking times of 15 minutes to adequately grade the fine aggregate sample.

\section{Specific Gravity Test}

The specific gravity of a substance, designated as Gs, is defined as the ratio of the density of that substance to the density of distilled water at a specified temperature. Since it is a ratio, the value of Gs does not depend on the system of units used and is a numerical value having no units. In soil mechanics, the specific gravity of soil solids is an important parameter and is a factor in many equations involving weight-volume relationships. Remember that the specific gravity of soil solids refers only to the solid phase of the three-phase soil system; it does not include the water and air phases present in the void space. For soil solids, Gs may be written as Pycnometer, glass rod, thermometer, balance (accuracy $0.1 \mathrm{~g}$ ) Clean and dry the density bottle. Wash the bottle with water and allow it to drain. Wash it with alcohol and drain it to remove water. Wash it with ether to remove alcohol and drain either. Table 2 shows the test results of specific gravity.

Table 2: Test Results of Specific Gravity

\begin{tabular}{|l|c|c|c|}
\hline \multicolumn{1}{|c|}{ Observation } & $\begin{array}{c}\text { Red } \\
\text { Soil }\end{array}$ & $\begin{array}{c}\text { Black } \\
\text { Soil }\end{array}$ & $\begin{array}{c}\text { River } \\
\text { Sand }\end{array}$ \\
\hline Test temperature Tc & $30 \mathrm{c}$ & $30 \mathrm{c}$ & $30 \mathrm{c}$ \\
\hline $\begin{array}{l}\text { Wt. of empty Pycnometer } \\
\text { (W1) }\end{array}$ & 0.425 & 0.425 & 0.425 \\
\hline $\begin{array}{l}\text { Wt. of Pycnometer + dry soil } \\
\text { (W2) }\end{array}$ & 0.869 & 0.760 & 0.886 \\
\hline $\begin{array}{l}\text { Wt. of Pycnometer + dry soil } \\
+ \text { water (W3) }\end{array}$ & 1.574 & 1.346 & 1.388 \\
\hline $\begin{array}{l}\text { Wt. of Pycnometer + water } \\
\text { (W4) }\end{array}$ & 1.346 & 1.539 & 1.660 \\
\hline
\end{tabular}

Weigh the empty bottle with stopper (W1). Take about 10 to $20 \mathrm{gm}$ of oven soil sample, which is cooled in desiccators. Transfer it to the bottle. Find the weight of the bottle and soil (W2). Put $10 \mathrm{ml}$ of distilled water in the bottle to allow the soil to soak completely. Leave it for about 2 hour. Again fill the bottle completely with distilled water put a stopper and keep the bottle under constant temperature water baths $\left(\mathrm{Tx}^{\circ}\right)$. Take the bottle outside and wipe it clean and dry note. Now determine the weight of the bottle and the contents (W3). Now empty the bottle and thoroughly clean it. Fill the bottle with only distilled water and weigh it. Let it be W4 at temperature $\left(\mathrm{Tx}^{\circ} \mathrm{C}\right)$. Repeat the same process 2 to 3 times to take the average reading of it.

\section{Results and Discussion}

The black cotton soil, silt clay soil and red soil for the present study were procured from Virudhunagar, Tamilnadu. Table 3 shows the notation for the various depths of soil used in the present study.

Table 3: Notation for the various depth of soil

\begin{tabular}{|c|c|}
\hline Soil & Depth \\
\hline A & $1.0 \mathrm{~m}$ \\
\hline B & $1.2 \mathrm{~m}$ \\
\hline C & $1.5 \mathrm{~m}$ \\
\hline D & $1.5 \mathrm{~m}$ \\
\hline
\end{tabular}


The specimen was extracted from the ground with the help of the core-cutter method. Further, to avoid any change in moisture content arising due to an increase or decrease in the atmospheric temperature, the specimens as derived were immediately placed in polythene covers. The various laboratory tests, as mentioned in Table 4, as per the Indian standard code, were conducted on the soil specimens.

Table 4: IS Code used for Testing

\begin{tabular}{|l|c|}
\hline \multicolumn{1}{|c|}{ Tests Performed } & IS Code Used \\
\hline Grain size analysis & IS:2720 (part 4)-1985 \\
\hline Field density test & IS:2720 (part 5)-1985 \\
\hline Specific Gravity & IS:2720 (part 3)-1985 \\
\hline $\begin{array}{l}\text { Classification and } \\
\text { Identification of soils for } \\
\text { General Engineering Purpose }\end{array}$ & IS:1498-1970 \\
\hline
\end{tabular}

\section{Sieve Analysis}

Grain size analysis test was conducted as per IS:2720 (part4)-1985 Particles size distribution of A, B, C Soils reveals that at points W (observations at $0.003 \mathrm{~mm}$ ), close lines corresponding to soil specimens $\mathrm{A}, \mathrm{B}, \mathrm{C}$ were observed. It reveals that all the soil specimens almost retain almost the same percentage of clay particles. Further, at point $X$ (corresponding to point 0.006 ), the percentage of slit retained was on a higher side in the case of soil $\mathrm{A}$ and lowest in the case of soil C. As we move further at point $Y$ (corresponding to point 0.6), the maximum percentage of fine sand has been found in soil $\mathrm{C}$ and maximum for soil $\mathrm{B}$ and minimum for soil A. The results of particles in soil A, B, C have also been shown in table 3. Further, investigation of Black cotton soils A, B, C was carried out with the help of Atterberg's limit tests. Table 5 and Figure 2 represent the particle size distribution for black cotton soil. The value of specific gravity for Red soil is: 2.7(fine-grained soil), Black soil is: 2.6(finegrained soil), and River sand is: 2.4(organic soil).

Table 5: Grain Size Analysis

\begin{tabular}{|l|c|c|c|}
\hline Particle size & Soil A & Soil B & Soil C \\
\hline Medium sand & 0.1 & 2.6 & 0.8 \\
\hline Fine sand & 15.31 & 6.4 & 16.9 \\
\hline Silt & 58.5 & 48.4 & 52.6 \\
\hline Clay & 26.1 & 32.6 & 29.7 \\
\hline
\end{tabular}

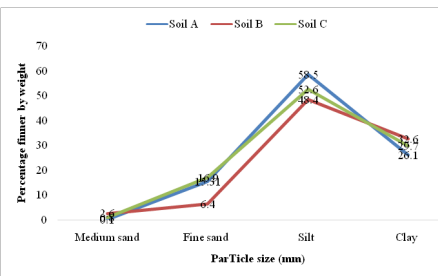

Figure 2: Particle Size Distribution Curve for Black Cotton Soil

\section{Conclusion}

- Finally, it is concluded that the soil examined is categorized as well-graded sand.

- A comparison is made between the normal soil sample and the mixed sample.

- Comparison of soils depends greatly on two experiments: the particle size distribution and the specific gravity test it is then highly recommended to verify the results of experiments 1 and 2 to check whether the comparison of the soil is accurate.

\section{References}

Abdi, Mahmood R., et al. "Effects of Random Fiber Inclusion on Consolidation, Hydraulic Conductivity, Swelling, Shrinkage Limit, and Desiccation Cracking of Clays." International Journal of Civil Engineering, vol. 6, no. 4, 2008, pp. 284-293.

Adeniji, F.A. "Recharge function of vertisolicvadose Zone in sub-Sahelian Chad Basin." International Conference on Arid Zone Ideology Hydrology and Water Resources, 1991.

Al-Khafaji, A.W.N., and O.B. Andersland. "Equations for Compression Index Approximation." Journal of Geotechnical Engineering, vol. 118, no. 1, 1992.

Arora, K.R. Soil Mechanics and Foundation Engineering. Standard Publisher, 2020.

Bowles, Joseph E. Physical and Geotechnical Properties of Soils. McGraw-Hill, 1996.

Chen, Fu Hua. Foundations on Expansive Soils. Elsevier, 1975.

Cokca, Erdal. "Use of Class C Fly Ashes for the Stabilization of Expansive Soil." Journal of Geotechnical and Geoenvironmental Engineering, vol. 127, no. 7, 2001. 
Dash, Sujit Kumar, and Monowar Hussain. "Lime Stabilization of Soils: Reappraisal." Journal of Materials in Civil Engineering, vol. 24, no. 6, 2012.

Ilamparuthi, K., and R.G. Robinson. Geotechnical Design and Practice: Selected Topics. Springer, 2018.

IS 1498-1970. Classification and Identification of Soils for General Engineering Purposes. Bureau of Indian Standards.

IS 2720 (Part 13) - 1986. Direct Shear Test. Bureau of Indian Standards.

IS 2720 (Part 15) - 1965. Determination of Consolidation Properties. Bureau of Indian Standards.

IS 2720 (Part 16) - 1987. Laboratory determination of CBR. Bureau of Indian Standards.

IS 2720 (Part 29) - 1975. Standard Proctor Test. Bureau of Indian Standards.

IS 2720 (Part 3) - 1980. Determination of Dry Density. Bureau of Indian Standards.

IS 2720 (Part 4) - 1985. Grain Size Analysis. Bureau of Indian Standards.

IS 2720 (Part 5) - 1985. Determination of Liquid and Plastic Limit. Bureau of Indian Standards.

IS 2720 (Part 8) - 1983. Determination of Water Content - Dry Density Relation using Heavy Compaction. Bureau of Indian Standards (BIS).
Pal, Sujit Kumar, and Ambarish Ghosh. "Compaction and Hydraulic Conductivity Characteristics of Indian Fly Ashes." Indian Geotechnical Conference, 2011, pp. 773-776.

Phani Kumar, B.R., and Radhey S. Sharma. "Effect of Fly Ash on Engineering Properties of Expansive Soils." Journal of Geotechnical and Geoenvironmental Engineering, vol. 130, no. 7, 2004.

Punmia, B.C., and Ashok Kumar Jain. Soil Mechanics and Foundations. Firewall Media, 2005.

Rajakumar. "California Bearing Ratio of Expansive Sub Grade Stabilized with Waste Materials." International Journal of Advanced Structures and Geotechnical Engineering, vol. 3, no. 1, 2014.

Ramamurthy, T.N., and T.G. Sitharam. Geotechnical Engineering (Soil Mechanics). S. Chand Publishing, 2008.

Seehra, S.S. "Practical Problems of Highway Construction in Black Cotton Soil Areas and In-Place Remedial Measures: A Case Study." $N B M \& C W, 2008$.

Terzaghi, Karl, et al. Soil Mechanics in Engineering Practice. Wiley, 1996.

Venkatramaiah, C. Geotechnical Engineering. New Age International, 2006.

\section{Author Details}

Anuja Narayanan, Assistant Professor, Department of Civil Engineering, Mepco Schlenk Engineering College, Sivakasi, Tamil Nadu, India, Email ID: anu_priya1031@yahoo.com 